\title{
How to Help Students Learn English Better: Towards Creating a Language Learning Culture
}

\author{
Saleh Saafin ${ }^{1}$ \\ ${ }^{1}$ Language Institute, University of Sharjah, Sharjah, United Arab Emirates \\ Correspondence: Saleh Saafin, Language Institute, University of Sharjah, Sharjah, United Arab Emirates
}

Received: February 23, 2019 Accepted: August 30, 2019 Online Published: September 2, 2019

doi: 10.5539/elt.v12n9p126 URL: https://doi.org/10.5539/elt.v12n9p126

\begin{abstract}
The purpose of this study was to investigate university students' perspectives of effective teaching that helped them learn English better. Adopting an interpretative approach to the research, the data was collected in three phases. In Phase One an interview was used and 17 university students studying English in Intensive English programs were interviewed. In Phase Two a qualitative questionnaire was used and 165 students responded to it. In Phase Three four students were interviewed for further information about the effective teaching characteristics identified in phases one and two. The findings of the study revealed that effective EFL teaching had two main dimensions: instructional skills and human characteristics. A wide range of categories and subcategories were classified under each dimension. Bearing in mind the descriptions and information the respondents gave throughout the Three Phases, the broader picture of effective teaching reflected the idea of a learning culture that effective teachers had an important role in creating.
\end{abstract}

Keywords: characteristics, effective teachers, English teaching, learning culture, students' perceptions

\section{Introduction}

This study investigated the perceptions of Arab tertiary students regarding the qualities of effective teachers of English as a foreign language (EFL teachers) at United Arab Emirates (UAE) higher education institutions. Improving learning outcomes is a goal that all educational institutions aspire to achieve. One way to reach this goal is improving teaching. Teacher training, mastery of the subject matter, student and teacher motivation, learning atmosphere, settings, etc. are important factors that help in improving teaching. There is an equally important factor which is effective teaching. Teacher characteristics and teaching behaviors are enormously important elements in student motivation and learning. Research indicates that effective teaching is one of the factors that influence the quality of learning (Perkins \& Solomon, 1989). Effective teaching can mainly be prescribed by teachers and students who are major factors in the whole teaching and learning process. Much of the research focuses on specific teaching behaviors identified by teachers and educational experts, but it does not focus enough on the perceptions of students on effective teaching qualities. To be effective, teachers need to consider the roles, biases and general mood of their students before planning how to teach them (Crowley, 1995; McCaslin \& Good, 1996). Learners know much better than anybody else what kind of teaching makes them learn better; therefore, this study refers to the real audience directly asking them to convey their views of what makes EFL teachers effective.

\section{Literature Review}

There are many teaching behaviors and qualities of effective teaching that are shared between general education and foreign languages. However, there are other qualities and teaching practices specific to various disciplines and that all teacher behaviors found in teacher effectiveness research may not apply to every discipline. Borg (2006) investigated the views of practicing and perspective EFL teachers on what distinguishes EFL teachers from teachers of other subjects. He presented five themes that make EFL teachers distinctive: nature of language

complex language content teaching, close relationship between teachers and learners and contrasts between native and non-native language teachers. Based on Borg's study, Lee (2010) introduced four similar dimensions peculiar to EFL teachers identified by Japanese college students: the complex nature of the subject matter, the content of teaching, teaching approach, and teacher personality. Accordingly, the reviewed studies in this research paper are only on the field of foreign languages. This may enable the researcher to review a wider range 
of studies investigating attributes of effective FL teachers.

Many studies have investigated the characteristics of EFL teachers from different perspectives. Since the current study explores students' perception of good EFL teachers, it is more logical to focus on the studies that sought the qualities of effective teachers from students' point of view.

Saafin (2008) identified the perceptions of 136 Arab university students in the UAE of the qualities and practices of the teachers they consider effective. The participants were asked to write their views on the teachers they had perceived as effective. The findings showed that the most frequent attributes emerged from the data were: treating students with respect, being flexible, being helpful, being friendly, having a sense of humor, helping students understand, giving students the chance to speak and ask questions, being dedicated, being fair, being a role model, being knowledgeable of his/her subject, being patient, and smiling. The participants of this study highly appreciated the human element in the English language teaching and learning process. Taqil \& Akbar (2014) investigated the perspectives of 150 EFL undergraduate Arab students in Kuwaiti. The data was collected through a 28 item questionnaire consisting of four general categories, i.e. English language proficiency, educational perception, organization and communication skills and social and emotional skills. The findings revealed that all these four categories were important for the students. However, the students gave more weight for the social and emotional skills than the other categories.

Kourieos and Evripidou (2013) sought the attributes of effective EFL university teachers perceived by Cypriot students. The data were obtained by means of a 35 item questionnaire administered to 110 students and focus group interviews involved 18 students. The results were grouped into three categories: personal and interpersonal characteristics, subject-matter knowledge and approach to language teaching. The researchers indicated that the findings of their study revolved around student-centered learning in which teachers were no longer authoritarians but rather involved students in classroom interactions and group tasks discussing real life topics and using authentic language.

Berlin (2000) interviewed 47 international students in an EFL program at the University of Arizona and then asked them to complete a qualitative questionnaire. The students identified five practices of good EFL teachers: taking into consideration the individual differences, making connections to the real world, establishing a good relationship with students, having a sense of humor and loving students.

Through a free writing instrument, Barnes (2010) asked105 students at a Korean university to describe in their own language effective EFL teachers. Five main categories emerged in this study: rapport, delivery, fairness, knowledge of the target language and organization and preparation. Barnes \& Lock (2013) sought to measure the importance that 222 Korean University students place on effective teacher attributes identified in the above mentioned study using a quantitative questionnaire. The findings showed that students put a lot of emphasis on rapport followed by delivery, impartiality, target language knowledge, and good preparation attributes.

Chen (2012) investigated 60 Thai university students' perceptions of the characteristics of effective EFL teachers using open-ended questionnaires and semi-structured interviews. He identified two main dimensions: personal traits dimension which included emotions, kindness, fairness, lenience and responsibility; and teaching dimension that consisted of lesson delivery, using English and Thai languages in teaching, organizing activities in classroom and creating classroom atmosphere. Meksophawannagul (2015) sought the viewpoints of 35 teachers and 613 Thai university students regarding effective English teaching using two questionnaires that included quantitative and qualitative items. The quantitative data revealed that rapport was the most important category for students followed by organization and preparation, delivery, fairness and knowledge and credibility, while teachers believed that the category of organization and preparation was the most important one followed by rapport, fairness, knowledge and credibility and delivery. The qualitative data showed that rapport items were important, but students gave more weight for these items. The qualitative data also revealed that well-prepared lessons and providing fun activities were important practices of effective teachers.

Liando (2010) investigated the characteristics of the best EFL teachers as perceived by 126 students and 28 teachers in a university setting in Indonesia. The data was collected from a 43 item questionnaire. The findings showed that both students and teachers agreed that best teachers should be friendly, intelligent and can explain things well, nice, make the course interesting, have a sense of humor, patient, give extra help, enthusiastic, give rewards and give a lot of homework. The results showed that personal traits were given more votes than academic qualities. Said (2017) investigated the perceptions of 270 undergraduate Indonesian students about effective EFL behaviors. The data were obtained through a questionnaire addressing seven areas of EFL teacher qualities, i.e. encouraging teacher contact, developing cooperation with students, encouraging active learning, giving prompt feedback, emphasizing time on tasks, communicating high expectations and respecting diversity 
in talents and ways of learning. The findings revealed that all categories were considered useful for students, but three of them were rated the highest: employing effective learning techniques, giving prompt feedback and communicating high expectations.

Overall, the reviewed studies demonstrated that the notion of effective teaching involves a wide range of dimensions, sub-dimensions and constructs which are not always easy to prescribe. The reviewed literature also indicated that while there is consensus on certain traits and behaviors of EFL teachers, some other qualities were not identified in some studies. This could be due to the fact that the reviewed studies investigated the perceptions of different students from different backgrounds, different cultures and different learning settings.

\section{Method}

\subsection{Research Design}

A qualitative study design was used to secure the information required. This study was conducted in three phases. In Phase One a semi-structured interview was used to obtain in-depth information necessary to describe the characteristics of effective EFL university teachers. The 17 participants in this phase came from four different higher educational institutions. In Phase Two, a questionnaire that consisted of 3 open-ended questions was used. These questions were used in the interviews in Phase One and proved to be the best informing questions. The purpose of this questionnaire was to see to what extent the data collected from interviews represented the views of a broader group of students. The sample of Phase Two consisted of 163 participants who did not participate in Phase One. In Phase Three follow up-interviews were conducted. The aim of these interviews was to further investigate some of the categories shared by participants in Phases One and Two. Four participants were interviewed in this phase.

\subsection{Site and Samples}

The present study was carried out in four Intensive English Programs in four major universities in the UAE. The population of this study was the Arab students who attend intensive English courses for one year on average before joining their vocational programs which were taught in English. The objective of the study was not to generalize results from the sample to the whole population nor to other populations, but rather to understand the perceptions of this group of Arab students of effective English teachers. In the light of this, purposive sampling was used in Phases One and Three. Opportunistic sampling was used in Phase Two. Males and females were represented in the three phases. Ages ranged between 18 and 20.

\subsection{Data Collection}

Using three data collection approaches helped the researcher to provide valid findings. This iterative development of the research instruments made the researcher confident that no single method would color his data.

\subsubsection{Phase One: Interviews}

Interviews were used to collect data in Phase One. The interview is considered to be a major research instrument that explores the interviewees' views of the world (Brown and Dowling, 1998). The interview helped the researcher to gain a clearer understanding of the perspectives of his interviewees. Interviews also gave the participants the freedom to express themselves and provide their own perceptions. Interviews: "enable participants to discuss their interpretations of the world in which they live from their point of view" (Cohen et al., 2000:267). The researcher used semi-structured interviews for Phases One and Three because this enabled him to control the interview direction and focus the inquiry on the topic of the study. These interviews were directed by a set of general themes rather than a list of predetermined questions. This gave the researcher more freedom to explore the interviewees' responses and capture the perceptions of the participants about effective teaching. A list of interview questions were piloted on three university students from the same population as the study sample. The questions were understandable for them and they gave answers that made sense in relation to the questions. The context of the interview entailed asking new questions that emerged during interviews in order to obtain a certain piece of information or verify another. The three interviews took from thirty-five to fifty minutes. After that 17 informative participants were identified by the supervisors of the IEP in the four higher education institutions. The interviewees were very informative, frank and motivated to talk about what makes English teachers effective. This enabled the researcher to collect very rich data. All interviews took place at the universities where the interviewees studied and all of them were conducted in Arabic and recorded after getting the participants' permission. 


\subsubsection{Phase Two: Open-Ended Questionnaires}

The second method of collecting data was the open-ended questionnaire. The questionnaire is one of the most frequent research tools that have been used in general education research (Oppenheim, 1992). The aim of this questionnaire was to get a deeper understanding of the perceptions of effective English teachers of a larger sample of Arab students. The researcher wanted to involve a bigger number of participants and identify their perceptions of effective teaching and check whether they shared the perceptions of the seventeen interviewees (small group) in Phase One. After the researcher finished analyzing the data collected from the interviews in Phase One, he constructed an open-ended questionnaire that consisted of 3 open-ended questions. These questions were used in the interviews in Phase One and proved to be the best informing questions. The questionnaire was piloted with two colleagues and two students who were not involved in the study. The pilot results revealed that the questions were clear and understandable. It took respondents from 20 to 35 minutes to complete the questionnaire. After that 165 students were recruited from the four study sites. They were asked to express their own point of view and not to influence each other's opinion. They took it seriously and most of them provided a considerable amount of data in Arabic.

\subsubsection{Phase Three: Follow up Interviews}

The aim of the follow up interviews was to get a deeper understanding of the characteristics of effective teachers that were extracted from the data of interviews and questionnaires in Phases One and Two. The researcher wanted to know exactly what students meant when they said, for example, that an effective EFL teacher should be an understanding person. Since there were many characteristics that were identified as important from the perspective of Arab students, the researcher could not cover all of them in his four interviews. Therefore, the high frequency categories were selected for more elaboration. Interview questions were constructed and then translated into Arabic. The interview was piloted with two respondents before it was used with the actual sample. Questions were clear and answers made sense in relation to the questions. The interviews lasted between 20-30 minutes each. After that four students from the four sites were recruited for this phase. They were motivated to talk about such characteristics which they all agreed on. The interviews were conducted in Arabic and recorded after getting the participants' permission.

\subsection{Qualitative Data Analysis}

The researcher opted for an analysis of data by hand because he wanted to absorb the data completely, become totally engaged with what the respondents said, and to read what was between the lines. In analyzing the data gathered by means of the semi-structured interviews, open-ended questionnaires and follow-up interviews, he used the grounded theory methods recommended by Strauss and Corbin (1998). It should be made clear that students' language does not always map with the professional language. Therefore, students' discourse was followed when it did not match with the professional one.

\section{Results}

A large number of categories were identified in the analysis of the qualitative data. These categories were classified under two major themes: instructional skills and human characteristics.

\subsection{Theme One: Instructional Skills}

The instructional skills theme consists of four main dimensions: teaching approach, learning resources, interaction and management. Each of these dimensions consists of a number of teaching practices that the respondents considered effective:

\section{Teaching approach}

A. Using suitable teaching ways

1. Using a variety of teaching ways

2. Using examples

3. Using a variety of teaching aids

4. Holding students' attention

5. Asking questions

6. Caring for teaching words

7. Willing to repeat explanation

8. Asking students to do things they did not teach (ineffective teacher) 
9. Giving no actual teaching (ineffective teacher)

10. Following a lecturing style (ineffective teacher)

B. Helping students understand

1. Checking students' understanding

2. Simplifying things

3. Taking into consideration individual differences

4. Reviewing previous lessons

5. Speaking clearly at a suitable speed

C. Giving interesting classes

1. Selecting a diversity of interesting topics

2. Not following the same teaching routine

3. Minimizing lecturing time

4. Organizing competition in classroom

5. Having fun

D. Efficient in testing

1. Giving appropriate assessment

2. Giving exams on a regular basis

3. Providing test practice

E. Giving homework

F. Benefiting students

G. Investing class time efficiently

H. Being well prepared

II. Learning resources

A. Giving handouts and worksheets

1. Diversity of materials

2. Found to be more useful for learning English than textbooks

3. Containing a lot of practice

B. Using computer technology

C. Investing the library

\section{Interactions}

A. Enabling students to practice speaking

1. Facilitating classroom discussions

2. Giving the chance for the students to talk about themselves

3. Involving students in authentic speaking projects

4. Allowing students to ask and answer questions

5. Communicating with students in English

6. Correcting students' speaking mistakes

B. Making students work in groups

C. Getting everyone involved

IV. Management

A. Classroom control

B. Punctuality 


\section{Implementation of rules}

To be aware of the importance of each category for the subjects of the current study, it is necessary to identify the frequency of each category under the instructional skills theme. Table 1 shows the frequency of the categories of each dimension of this theme.

Table 1. Frequency of categories under each dimension of the instructional skills theme

\begin{tabular}{ll}
\hline Category of Each Dimension & Frequency \\
\hline I. Teaching approach & \\
A. Using suitable teaching ways & 194 \\
B. Helping students understand & 181 \\
C. Giving interesting classes & 147 \\
D. Efficient in testing & 82 \\
E. Giving homework & 62 \\
F. Benefiting students & 56 \\
G. Investing class time efficiently & 31 \\
H. Being well prepared & 29 \\
II. Learning resources & \\
A. Giving handouts and worksheets & 177 \\
B. Using computer technology & 94 \\
C. Investing the library & 84 \\
III. Interactions & \\
A. Enabling students to practice speaking & 123 \\
B. Making students work in groups & 51 \\
C. Getting everyone involved & 50 \\
IV. Management & \\
A. Classroom control & 41 \\
B. Punctuality & 21 \\
C. Implementation of rules & 17 \\
\hline
\end{tabular}

Table 1 ne shows that the most emphasized dimension was the teaching approach. It is the core of the whole instructional skills theme. The highest rated categories classified under this dimension were using suitable teaching methods, helping students understand and giving interesting classes. These three categories are interrelated and represent the essence of the teaching process for the students.

"He tended to repeat things during his explanation so that he can make sure that the students understand."

"He spoke in a way that suited our level."

"At the beginning of the class, she reviewed what we took before."

"When the teacher explained the meaning of a new word, he gave us its equivalent meaning in English. Another method could be using a picture. Sometimes the teacher acted so that we can understand."

"He held the attention of students by asking questions."

"He selected interesting topics such as marriage in your country and this attracts you."

"Long explanations of some teachers may lead to boredom and lack of interest."

In the learning resources dimension, the study subjects believed that using a variety of learning resources helped them a lot in learning English and found it much more useful than just relying completely on textbooks. The category of giving students handouts and worksheets got the highest number of votes among the items classified 
under this dimension.

"He should use as many exercises and practices as he could from outside the textbook. These materials are more useful than the textbook itself."

"She brought us reading materials from the internet, magazines and the newspapers."

The most frequent category under the interaction dimension was enabling students to practice speaking English. The participants considered this very useful for developing their English language.

"He involved students in discussions and enabled them to express their opinions. In this case students learned how to use the language and would be brave enough to speak in English."

"She let us talk about what happened to us the day before."

"Every three weeks we tended to go with our teacher to the cafeteria and talk about our food or our life."

The participants identified the classroom control category under the management dimension as the most significant item. They believed that without classroom control disorder would prevail in class and the learning process would be affected negatively.

"I didn't like teacher number eight. There was no class control. If there is class control, learning will occur."

"She had the ability to control the class. I also noticed that she managed to control those students who tend to chat in other classes and this gives a better chance for learning."

\subsection{Theme Two: Human Characteristics}

This theme consists of two main dimensions: interpersonal characteristics and personal characteristics. Each of these dimensions consists of a number of qualities of effective EFL teachers:

\section{Interpersonal characteristics}

A. Having a friendly manner

1. Building bridges between teachers and students

2. Interacting with students outside the classroom

3. Interacting informally with students

4. Socializing with students

5. Treating students as friends or family members

6. Smiling at the students

7. Being friendly

B. Helping students

1. Giving advice to students

2. Helping students in academic related issues

3. Helping weaker students

4. Giving good marks

5. Helping students in personal matters

C. Encouraging students

D. Being flexible and willing to compromise

E. Respecting students

F. Creating a good atmosphere

G. Treating students as equal

H. Listening to students

I. Identifying/meeting students' needs

\section{Personal characteristics}

A. Having a sense of humor

B. Being dedicated 


\section{Being energetic \\ D. Being patient \\ E. Being likeable}

To be able to know students' priorities among the categories of the two dimensions of the human theme, the frequency of these categories was identified in Table 2.

Table 2. Frequency of categories under each dimension of the human characteristics theme

\begin{tabular}{ll}
\hline Categories of Each Dimension & Frequency \\
\hline I. Interpersonal characteristics & \\
A. Having a friendly manner & 161 \\
B. Helping students & 112 \\
C. Encouraging students & 70 \\
D. Being flexible and willing to compromise & 60 \\
E. Respecting students & 57 \\
F. Creating a good atmosphere & 57 \\
G. Treating students as equal & 37 \\
H. Listening to students & 13 \\
I. Identifying/meeting students' needs & 12 \\
II. Personal characteristics & \\
A. Having a sense of humor & \\
B. Being dedicated & 84 \\
C. Being energetic & 42 \\
D. Being patient & 29 \\
E. Being likeable & 25 \\
\hline
\end{tabular}

Table 2 shows that the study subjects put much more emphasis on the dimension of interpersonal characteristics than the dimension of personal characteristics. The most frequent quality of an effective teacher under the dimension of interpersonal characteristics was being friendly. The respondents highly appreciated the teachers who showed them friendliness and believed that it has a positive reflection on learning English.

"He respects students and treats them in friendly manner."

"He should deal with students outside the class like a friend or a brother and not just a teacher who doesn't joke and laugh with students."

"He has a friendly relationship with students inside and outside the class. This gives the student a sense of security."

"He likes his students and considers them like his children."

Helping students was the second most frequently mentioned category classified under the dimension of interpersonal characteristics. Effective teachers for them were those who helped them inside and outside the class.

"She tried to help us when we face a problem in learning English."

"He asked students to go to his office when they needed to know a certain thing about the subject."

"He should accept weak students and help them."

"If a student's mark is low, he should increase the number of tests so that he can increase his mark."

The second dimension of the human theme was personal characteristics. Table 2 shows that having a sense of humor was given the highest number of votes. They mentioned that one way their perceived effective teachers were able to maintain their interest in class and create a good learning atmosphere was through their sense of 
humor.

"He used fun and joked while teaching and as a result he created an interesting atmosphere and made the students like the class."

"He was funny with us so that we may not feel bored. Some other teachers are boring to the extent that we benefit nothing from them and we wanted their classes to finish quickly so that we can leave the classroom."

"I sometimes feel sleepy because this teacher doesn't joke with us."

\section{Discussion and Conclusion}

The findings of this study showed that there were a wide range of attributes and behaviors of effective EFL teachers that were classified under two major themes: instructional skills and human theme. Both themes were consistent with the reviewed research studies (Berlin, 2000; Saafin 2008; Barnes, 2010; Barnes \& Lock 2013; Liando, 2010; Chen 2012; Kourieos \& Evripidou, 2013; Taqil \& Akbar 2014; Meksophawannagul 2015; Said, 2017). The instructional skills theme highlighted the active role of teachers in helping students learn English. The respondents identified four dimensions under the instructional skills theme: teaching approach, learning resources, interactions and management. The dimension of teaching approach included a lot of teaching skills and practices that were classified under various categories. The study subjects considered that using suitable teaching methods and helping them understand as the most significant practices of effective teachers. Learning a foreign language is not an easy task and therefore students need their teachers to try all ways to help them face difficulties and learn the language. Also the respondents strongly emphasized the necessity of having interesting classes by selecting interesting topics, changing the teaching routine, avoiding lecturing style, enabling them use personalization language and talk about themselves and their lives, organizing competitions and having fun. Such practices of effective teachers hold the attention of students and make learning more authentic and more enjoyable. The second dimension of the instructional theme was learning resources. The data showed that effective teachers did not rely solely on the textbooks to teach English but rather they used other learning resources such as handouts, worksheets and computer technology. The study subjects frequently indicated that textbooks should not be the only learning resource for teaching English. Diversifying the learning resources gave them the chance to practice the language more and released them from the routine instructions they should follow in each chapter of their textbooks and made their classes more useful and interesting. The third dimension was interaction which necessarily gave the participants the opportunity to practice speaking the target language. Almost all of them highlighted the need for enabling them to practice speaking English and use it as a means of communication inside and outside the classroom. This is how they could develop their language skills. In fact they criticized the teachers who talked most of the time in class leaving little time for students to interact using the target language. The fourth dimension of the teaching approach was management. The students felt that class control was the most important aspect of classroom management. Effective teachers were able to control their classes and this is crucial for creating the right atmosphere for teaching and learning.

The second major theme of effective teaching emerging in this study was the human theme. The findings showed that the respondents gave more votes for the human qualities than the teaching skills. This overemphasis on human traits of teachers was consistent with the findings of Saafin (2008); Taqil and Akbar (2014); Barnes and Lock (21013) and Liando (2010). This shows that the human element in the Arab culture is very important. The respondents mainly identified interpersonal and personal characteristics in the human theme. Teachers' friendliness was found to be a very significant factor in teachers' interpersonal relationship with students. Friendly teachers were expected to build bridges with students, interact with them inside and outside the classroom, be informal and deal with them as friends. The participants also put a lot of emphasis on being helpful as a characteristic of good teachers who were willing to listen to students' problems, give them advice and show support.

Regarding the personal characteristics, the study subjects believed that having a sense of humor is a very important one. The perceived effective teachers were able to maintain the interest of their students in class and create a good learning atmosphere through their sense of humor. Teachers demonstrated their sense of humor by joking, making funny comments and making body movements. The respondents indicated that teachers' sense of humor made classes interesting and held their attention.

\section{From Effective English Teaching to Creating a Language Learning Culture}

Having an overview of the descriptions the respondents gave throughout the Three Phases, it can be seen that the essence of the data was its orientation towards the idea of creating a learning culture for effective language teaching. Reviewing the data through different lenses showed that the respondents highlighted a web of 
instructional behaviors and practices as well as personal and interpersonal characteristics of effective teachers that altogether drew a bigger picture. This picture portrayed a learning culture that enabled the participants to learn English more effectively.

One of the significant aspects of the effective English language learning culture that the data of the current study revealed was diversification. The respondents talked about the advantages of using various teaching methods, classroom activities, teaching aids and learning resources in helping them learn English. The diversity of such practices facilitates learning and makes classes more interesting. Maximum involvement of students and getting everyone involved in learning and practicing the target language is another important element of the desired learning culture. The participants talked about engaging them in classroom discussions, group work, asking and answering questions, doing authentic speaking projects, etc. They especially highlighted the usefulness of practicing English in various real situations and in different settings such as classrooms, teachers' offices corridors, events halls and cafeterias where they can use English freely. The participants were persistent throughout the three study stages that they need to practice English as much as possible. They believed that this helped them a lot in learning the language. The data also showed that having a suitable learning atmosphere is an essential component of an effective learning culture. Creating a good learning environment overlaps with many other characteristics and practices of effective teachers identified in the current study such as friendliness, encouragement, having a sense of humor, having fun, maintaining class control, interacting with students inside and outside the class, showing flexibility and being helpful. As we can see, the learning culture that the data reflected helps students learn English better. It keeps them busy and engage all of them in learning English through various teaching and learning practices in a friendly, motivating, interesting and most importantly encouraging atmosphere.

The above mentioned aspects of a learning culture were also identified by other researchers. Shepherd (2000) emphasized the significance of the authenticity aspect. He said that it is not enough to make classes more interesting; students should be able to use knowledge in real-world settings. In this view teachers who take their students to the cafeteria to talk informally over coffee are doing much more than simply being friendly and approachable. Similarly, Brown et al. (1989) stated that what is learned cannot be separated from how it is learned. They indicated that situations are an integral part of learning. Also, Heo et al. (2018) identified six themes of the learning culture through which high performing education was recognized in classrooms at schools in Finland and South Korea: teacher's autonomy in teaching, authenticity in learning, relationships between teachers and students, learning assessment, student engagement, and student well-being. As it can be seen, many aspects of the effective learning culture were identified in this study as well as by other researchers. However, a learning culture is still a broad concept. It is not easy to prescribe certain elements as components of a learning culture that we can follow in order to create and maintain it but rather it constitutes a wide range of interrelated factors that contribute to learning.

Understanding that students perceive effective teaching as behaviors and practices embedded in an effective English language learning culture is significant because it implies a new view of effective EFL teaching. In fact, the idea of an effective learning culture and insights into the characteristics of that culture, perhaps reveal an emerging theory of effective teaching and learning of English as a foreign language.

\section{References}

Barnes, B. D., \& Lock, G. (2010). The attributes of effective lecturers of English as perceived by students in a Korean university. Australian Journal of Teacher Education, 35(1), 139-152. https://doi.org/10.14221/ajte. $2010 \mathrm{v} 35 \mathrm{n} 1.2$

Barnes, B. D., \& Lock, G. (2013). Student perceptions of effective foreign language teachers: A quantitative investigation from a Korean university. Australian Journal of Teacher Education, 38(2), 19-36. https://doi.org/10.14221/ajte.2013v38n2.2

Berlin, L. N. (2000). Toward a “Working Definition” of Effective Language Instruction in the Multicultural ESL Classroom. Ph D Dissertation. The University of Arizona.

Borg, S. (2006). The distinctive characteristics of foreign language teachers. Language Teaching Research, 10(1), 3-31. https://doi.org/10.1191/13621688061r182oa

Brown, A., \& Dowling, P. (1998). Doing Research/Reading Research. London: Falmer Press.

Brown, J.S., Collins, A., \& Duguid, P. (1989). Situated cognition and the culture of learning. Educational Researcher, 18(1), 32-42. https://doi.org/10.3102/0013189X018001032

Chen, J. (2012). Favorable and unfavorable characteristics of EFL teachers perceived by university students of 
Thailand. International Journal of English Linguistics, 2(1), 213-219. https://doi.org/10.5539/ijel.v2n1p213

Cohen, L., Manion, L., \& Morrison, K. (2000). Research methods in education (5th ed.), Routledge Falmer, London.

Crowley, P. (1995). Listening to what readers tell us. Voices from the Middle, 2(2), 2-12.

Heo, H, Leppisaari, I., \& Lee, O. (2018) Exploring learning culture in Finnish and South Korean classrooms. The Journal of Educational Research, 111(4), 459-472. https://doi.org/10.1080/00220671.2017.1297924

Kourieos, S. \& Evripidou, D. (2013), Students' Perceptions of Effective EFL Teachers in University Settings in Cyprus. English Language Teaching, 6(11), 1-16. https://doi.org/10.5539/elt.v6n11p1

Lee, J. (2010). The uniqueness of EFL teachers. Perceptions of Japanese learners. TESOL Journal, 1(1), 23-48. https://doi.org/10.5054/tj.2010.214881

Liando, N. (2010). Students' vs. teachers' perspectives on best teacher characteristics in EFL classrooms. TEFLIN Journal, 21(2), 118-136. https://doi.org/10.15639/teflinjournal.v21i2/118-136

McCaslin, M., \& Good, T. (1996). Listening to Students. New York: Harper-Collins.

Meksophawannagul, M. (2015). Teacher and learner views on effective English teaching in the Thai context: The case of engineering students. English Language Teaching, 8(11), 99-116. https://doi.org/10.5539/elt. v8n11p99

Oppenheim, A. N. (1992). Questionnaire Design, Interviewing and Attitude Measurement. London: PINTER.

Perkins, D. N., \& Solomon, G. (1989). Are cognitive skills context bound? Educational Researcher, 18(1), 16-25. https://doi.org/10.3102/0013189X018001016

Saafin, S. (2008). Arab tertiary students' perceptions of effective teachers. Learning and teaching in higher education: Gulf perspectives, 5(2).

Said, M. (2017). Effective behavior of EFL teachers as perceived by undergraduate students in Indonesia. English Language Teaching, 10(10), 50-62. https://doi.org/10.5539/elt.v10n10p50

Sheperd, L. (2000). The role of assessment in a learning culture. Educational Researcher, 29(7), 1-14. https://doi.org/10.3102/0013189X029007004

Strauss, A. \& Corbin, J. (1998). Basis of Qualitative Research: Techniques and Procedures for Developing Grounded Theory (2nd ed., pp. 101-121). Thousand Oaks, CA: Sage Publications, Inc.

Taqil, H., Al-Nouhl, N., \& Akbarl, R. (2014). The perspectives of students in the College of Basic Education on the characteristics of effective English language teachers. English Language Teaching, 7(3), 121-133. https://doi.org/10.5539/elt.v7n3p121

\section{Copyrights}

Copyright for this article is retained by the author(s), with first publication rights granted to the journal.

This is an open-access article distributed under the terms and conditions of the Creative Commons Attribution license (http://creativecommons.org/licenses/by/4.0/). 